Article: "Does the Wording of Syllabi Affect Student Course Assessment in Introductory Political Science Classes?"

Author: John T. Ishiyama, Stephen Hartlaub

Issue: Sept. 2002

Journal: PS: Political Science \& Politics

This journal is published by the American Political Science Association. All rights reserved.

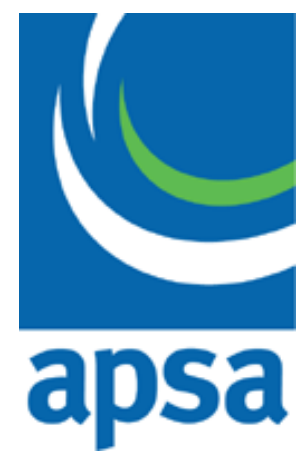

APSA is posting this article for public view on its website. APSA journals are fully accessible to APSA members and institutional subscribers. To view the table of contents or abstracts from this or any of APSA's journals, please go to the website of our publisher Cambridge University Press (http://journals.cambridge.org).

This article may only be used for personal, non-commercial, or limited classroom use. For permissions for all other uses of this article should be directed to Cambridge University Press at permissions@cup.org . 


\title{
Does the Wbrding of Syllabi Affect Student Course Assessment in Introductory Political Science Classes?*
}

\author{
John T. Ishiyama, Truman State University \\ Stephen Hartlaub, Frostburg State University
}

A s college professors, we produce and distribute syllabi in our courses. In writing syllabi, faculty may affect the way that students perceive them without intentionally doing so. Obviously, the required readings and assessment techniques employed (e.g., papers versus multiple choice exams) affect a student's perception of the difficulty of an instructor. In addition, the wording of the syllabus itself may also affect student perceptions. In particular, the language used by faculty members in describing course requirements, attendance policy and other aspects of the course may influence student perceptions of the faculty member. This paper explores the impact of the language that appears in the syllabus on student perceptions of the instructor. We focus on the use of "rewarding" or "punishing" language in describing course requirements.

There is a good deal of literature that discusses the psychological impact of language phrased as a reward or as punishment. In designing a syllabus, faculty often phrase course requirements, such as attendance, in terms of "rewarding" good attendance or "punishing" poor attendance. Does this phrasing affect student perceptions of the course? Does it affect whether students are comfortable

John Ishiyama is an associate professor of political science at Truman State University and research coordinator for the Ronald E. MCNair Program. He has published widely in both political science and higher education journals. His teaching and research interests focus on comparative politics, with a special emphasis on democratization and political party development in the former USSR and Eastern Europe. He can be reached at jishiyam@truman.edu.

Stephen Hartlaub is an assistant professor and chair of the political science department at Frostburg State University. His eclectic research agenda ranges from pedagogical theory and practice to political philosophy and N ew Urbanism. He received his Ph.D. from Michigan State University. He can be reached at shartlaub@mail.frostburg.edu. approaching their professors for help? Does it affect whether students elect to take the course? Are more advanced students more sensitive than underclassmen to the subtleties of language?

In this article, we examine the impact of syllabi wording on how students assess a hypothetical instructor for an introductory political science course at a medium-sized state institution. Student participants were recruited from political science classes at this institution and randomly assigned to two groups. The groups were asked to review a sample syllabus from an introductory political science class and answer a number of questions regarding the instructor, as well as a few demographic questions. The syllabi were identical except for the wording of the requirements. For one group, the requirements were expressed in "rewarding" terms; for the other, the requirements were expressed in "punishing" terms.

\section{Lterature}

Syllabi are a central part of teaching for a number of reasons (Duffy and Jones 1995). Syllabi can improve communication between instructors and students, and clarify course expectations (Behnke and Miller 1989; Smith and Razzouk 1993). Indeed the syllabus is

a formal statement of what the course is about, what students will be asked to do, and how their performance will be evaluated. Unlike the comments an instructor makes in class, it is a lasting statement to which students can refer again and again. Careful construction of the syllabus reduces ambiguity and is the first step toward producing an environment in which student learning can flourish. ("Chapter 3-Preparing a Course," in Teaching Handbook, The Ohio State University, Office of Faculty and TA Development; see also: Altman 1989; Danielson 1995; Matejka and Kurke 1994)

To date, however, very little research has empirically analyzed the syllabus as an "independent" variable affecting students. The few exceptions focus mainly on classroom socialization and performance (Duffy and Jones 1995). For example, Danielson (1995) argues that the syllabus can contribute to the classroom socialization process by serving as a contract (analogous to the psychological contract operating in organizations) and by reducing classroom uncertainties. Robles (1993) has investigated the empirical link between the content of the syllabus and how this content affects student expectations about the course (see also Becker and Calhoon 1999). Kern (1990) finds that a competencybased syllabus, in which student competencies required for the course as well as competencies to be developed during the course were outlined and explained, results in increased student performance. Serafin (1990) also finds that changes introduced to the course syllabus affected the final grade performance of students. Indeed, she finds that the more explicit is the course syllabus in terms of number of objectives, content, instructional resources, and grading components, the better the performance of college students (see also Harris 1993; Schlesinger 1987).

A study that more directly addresses syllabus effects on student perceptions of instructors was conducted by Perrine, Lisle, and Tucker (1995). They demonstrate that the syllabus can affect a student's willingness to seek help from college instructors. They explored the willingness to seek help as a function of student age, class size, and whether an explicit supportive statement is placed on the syllabus. Students $(\mathrm{N}=104)$ read brief syllabi of two courses in which class size and an offer of outside-of-class help from the instructor were manipulated. The results show that the students were more likely to express willingness to seek support from an instructor when the instructor explicitly offered outside help on the syllabus. In addition, there is a significant effect for age on support seeking. Younger (under 25) and older students do not differ significantly in their willingness to 
seek help in the supportive condition, but younger students are significantly less willing than older students to seek help in the neutral condition. These findings suggest that instructors might be able to encourage more students to seek outside-of-class help by placing supportive statements on the class syllabus.

Most studies, however, have not directly examined how subtle differences in the wording of syllabi affect student expectations. Although to an idealized rational decision maker there should be no difference between being rewarded three extra points for good attendance, and being punished by losing three extra points for less then perfect attendance, to impressionable students the wording of requirements is likely to have some effect. Indeed, for students it is likely that positive inducements create an "alliance and a spirit of good will" that "create an obligation for the giver to fulfill the promises...creat[ing] a sense of loyalty and mutual aid." Whereas, in negative inducements, or threats of punishment, "The adversary relationship is made explicit"

(Stone 1988, 270).

In this paper we are primarily concerned with the wording of requirements, i.e., whether the requirements are expressed in "rewarding" versus "punishing" language. There has been consistent, though limited, interest in the different effects of the language of inducements. Baldwin (1971a, 1971b) explored the impact of positive versus negative sanctions in international bargaining. Tjosvold (1995) explored the relationship between rewarding and punishing and the perceptions of those affected. In general, those who were rewarded thought power was used more fairly, and had more positive attitudes towards those in power, in contrast to those who were punished. In a similar way, teachers who phrase their syllabi in rewarding versus punishing language may affect student perceptions of them. The same requirements, expressed differently, may lead to very different student evaluations of the faculty member.

\section{Design}

In examining the impact of syllabus wording on students' assessments of introductory political science courses at a medium-sized state institution, we recruited 88 students from political science classes, and randomly assigned them to two groups of 44 students
Whereas the rewarding syllabus reads:

If for some substantial reason you cannot turn in your papers or take an exam at the scheduled time you should contact me prior to the due date, or test date, or you will only be eligible for $80 \%$ of the total points.

We tried to vary the language in only subtle ways to avoid great and obvious differences between the two syllabi. For example, in the syllabi we use phrases such as "students should complete all readings," or "students must complete all readings."

Section 1 of the questionnaire asked five questions about student perceptions of the instructor. The first questions asked: "Based on the information in the syllabus, do you think you would be comfortable talking to this professor outside of class?" We asked students to assess whether they would be "Very Comfortable," "Comfortable," "Not Very Comfortable," or "Not at all comfortable" Our hypothesis is that students will feel more comfortable talking to instructors who use rewarding language as opposed to instructors who use punishing language.

The second question asked: "Based on the information in the syllabus, please rate how difficult you think the class would be?" We asked students to respond using the following set of responses: "Very Difficult," "Not Very Difficult," "Difficult," "Not at all Difficult." Faculty often phrase the syllabus in harsher language in order to signal that they are a difficult instructor. Our prediction is that students will pick up on these signals and rank the instructor for the "punishing" syllabus as more difficult. The fourth question asked if the students were inclined to take the class, our prediction being that students will assess the instructor with the "rewarding" syllabus more favorably and be more likely to take the class.

The second section of the questionnaire asked a series of demographic questions, regarding gender, race, and year in school. Only one of these was directly related to the hypotheses. Question 8 asked for how many years the student had attended the university. In asking this question we were interested in whether students learn to glean clues from syllabi as they progress through academia. If they do, upperclassmen would be more attuned to these clues on the syllabus than underclassmen. In this case we used the number of years that the student reported having attended the university, because many students who report being "sophomores" in terms of credit hours, 
are really only freshmen in terms of actual time spent at the university. Since experience with the university environment is of concern here, the use of the reported number of years having attended the university is more appropriate than reported official class rank.

Similarly, question 11 asks students for their current grade point average (GPA). Our prediction is that students with a higher GPA will be more sensitive to the subtle clues in the syllabus. If they are better students, it may be because they are better at interpreting what the teacher wants, and a large part of this information would be present in the syllabus.

In sum our hypotheses are as follows:

Hypothesis 1a: Students will generally feel more comfortable approaching the professor of the reward syllabus than the punish syllabus.

Hypothesis 1b: First- and second-year students will be more affected by the differences in language exhibited by the syllabi than more senior (third-year and beyond) students. This is an expectation consistent with the findings of Perrine, Lisle, and Tucker (1995).

Hypothesis 2: Students will rate the class represented by the punish syllabus as being more difficult than the class represented by the reward syllabus.

Hypothesis 3: Students will be more likely to take the class with the reward syllabus than the class with the punish syllabus.

Hypothesis 4: Students with a higher GPA will be more sensitive to the subtleties of the language presented by the syllabus. Thus, students with higher GPAs will be more likely to differentiate between the reward syllabus and the punish syllabus.

\section{Results}

Turning to the results, when crosstabulating the estimated "approachability" of the faculty member by the type of syllabus (see Table 1 at <www.apsanet. org/PS/sept02/ishiyama.cfm>), there was a significant difference (chi-square $=$ $4.14, \mathrm{p}=.04$ ) when comparing across the two syllabi, with students much more likely to say that they were uncomfortable approaching the faculty member after reading the punish syllabus as opposed to the reward syllabus. Further, when controlling for number of years at the university, it appears that the most affected by the wording of the syllabus were first- and second-year students more so than third-year and beyond students (See Table 3 on line). As indicated by the results of the Fisher's exact test (see Tables 2 and 3 at <www.apsanet.org/PS/ sept02/ishiyama.cfm>), first- and secondyear students are much more likely to report being uncomfortable approaching the faculty member under the punish syllabus condition, than the reward syllabus condition, in contrast to third-year and beyond students. These results support hypotheses 1a and $1 \mathrm{~b}$, which suggest that the wording of the syllabus affects the students' perception that the faculty member is approachable, and that this is especially true for younger students. The results also lend further support to the findings of Perrine, Lisle, and Tucker (1995).

However, the results of the analysis do not support hypotheses 2 and 3. Indeed, when examining the students' estimate of the degree of difficulty of the course by type of syllabus, there is no significant difference between the two test conditions (chi-square $=2.26$, see Table 4 at <www.apsanet.org/PS/sept02/ ishiyama.cfm>). As with hypotheses 1a and $1 \mathrm{~b}$, we further tested the relationship controlling for number of years in school. However, even when controlling for years in school, we find no significant relationship between estimated difficulty of the course and the wording of the syllabus (chi-square for first- and second-year students $=.56$, and chisquare for third-year and beyond students $=1.78$ ). In other words, the students' estimates of the class's difficulty are due to some factor other than the syllabus's wording.

Similarly, there appears to be no significant difference between the two test conditions and the students' estimated likelihood that they would take the course (chi-square $=2.26$ ). This is not surprising given that student decisions about whether to take a course are more likely to be affected by considerations such as whether the course is required for the student's major.

Finally, when examining the relationships between each of the three dependent variables (whether the student was comfortable approaching the professor, the student's estimate of course difficulty, and whether the student was likely to take the course) with the syllabi conditions, controlling for GPA there are significant differences between the two syllabi conditions, with students with higher GPAs (3.00 and above) more likely to view a faculty member as unapproachable under the punish-syllabus condition, and significantly more likely to view the class as more difficult under the punish condition than the reward condition (see Tables 6 and 7 at <www. apsanet.org/PS/sept02/ishiyama.cfm>). However, and consistent with the findings above, whether the student found it likely that he or she would take the class is unrelated to the syllabus condition.

On the other hand, for students with GPAs less than 3.00 (see Table 7 at $<$ www.apsanet.org/PS/sept02/ishiyama. $\mathrm{cfm}>$ ), there are no significant differences between the syllabi conditions. Taken together, these results indicate that students with higher GPAs are more sensitive to the language of the syllabi, and generally differentiate between rewarding and punishing language, a finding that supports hypothesis 4 .

\section{Discussion and Conclusions}

Although it is tempting to discuss the effects of syllabi wording on retention, graduation rates, and other performance measures, these issues lie far beyond the scope of the results of our experiment. Nonetheless, the results suggest that students with high GPAs appear to be better at picking up subtle differences in syllabus language, more so than students with lower GPAs. This is not particularly surprising, as successful students are successful precisely because they pick up such subtle clues, and often navigate classes based upon what they perceive to be "what the instructor wants."

However, that first- and second-year students are particularly sensitive to the wording of the syllabi, especially whether they view the faculty member as approachable, is a potentially useful finding, which supports earlier work that suggested a connection between the wording of a syllabus and the willingness of students to seek help from the instructor (Perrine, Lisle, and Tucker 1995). It also suggests that faculty members should be particularly sensitive to the wording of syllabi with younger students, who are more likely to be intimidated by wording couched in punishing terms. In an era when university administrations place much emphasis on student retention (particularly among underclassmen), syllabi wording may be an important factor in the student's perception of faculty, and the willingness of faculty to be supportive of the student's education. Such perceived faculty support, as much research has noted, is a crucial factor in a student's decision to remain in school (for a discussion see Nnadozie, Ishiyama, and Chon 2001). Thus, making faculty aware of the importance of syllabi wording may be an effective way to improve student retention to the university in general, and to political science classes in particular. 


\section{Note}

*An earlier version of this paper was presented at the Annual Meeting of the Midwest
Political Science Association, Palmer HouseHilton, April 19-22, 2001. Chicago, Illinois.

\section{References}

Altman, H.B. 1989. "Syllabus shares "What the Teacher Wants.", The Teaching Professor 3 (May): 1-2.

Baldwin, David. 1971a. "The Power of Positive Sanctions." World Politics 24 (January): 19-38.

—. 1971b. "Thinking about Threats." Journal of Conflict Resolution 15:71-78.

Becker, Angela H., and Sharon K. Calhoon. 1999. "What Introductory Psychology Students Attend to on a Course Syllabus." Teaching of Psychology 26:6-11.

Behnke, R., and P. Miller. 1989. "Information in Class Syllabus May Build Student Interest." Journalism Educator 44:45-57.

Danielson, Mary Ann. 1995. "The Role of the Course Syllabi in Classroom Socialization." Bloomington: Indiana University, ERIC Clearinghouse for Social Studies/Social Science Education, ED387845.

Duffy, Donna Killian, and Janet Wright Jones. 1995. Teaching Within the Rhythms of the Semester. San Francisco: Jossey-Bass.
Harris, Mary McDonald. 1993. "Motivating with the Course Syllabus." The National Teaching an Learning Forum 3(1): 1-3.

Kern, R. 1990. "Use Of Competency-Based Course Syllabus and Its Effects on Student Performance in Introductory Computer Courses." Community/Junior College Quarterly of Research and Practice 14:115-22.

Matejka, Ken, and Lance B. Kurke. 1994. "Designing a Great Syllabus." College Teaching 42:115-19.

Nnadozie, Emmanuel, John Ishiyama, and Jane Chon. 2001. "Undergraduate Research Internships and Graduate School Success." Journal of College Student Development 42:145-56.

Perrine, Rose M., James Lisle, and Debbie L. Tucker. 1995. "Effects of a Syllabus Offer of Help, Student Age, and Class Size on College Students' Willingness to Seek Support from Faculty." The Journal of Experimental Education 64:41-52.
Robles, Alfredo. 1993. "How 'International' Are International Relations Syllabi?" PS Political Science \& Politics 26:526-28.

Schlesinger, A.B. 1987. "One Syllabus That Encourages Thinking, Not Just Learning." The Teaching Professor (August): 8.

Serafin, Ana Gil. 1990. "Course Syllabi and Their Effects on Students' Final Grade Performance." Bloomington: Indiana University, ERIC Clearinghouse for Social Studies/Social Science Education, ERIC: ED328202.

Smith, R., and N. Razzouk. 1993. "Improving Classroom Communication: The Case of the Course Syllabus." Journal of Education for Business 68:215-22.

Stone, Deborah. 1988. Policy Paradox: The Art of Political Decision Making. New York: W.W. Norton \& Company.

Tjosvold, Dean. 1995. "Effects of Power to Reward and Punish in Cooperative and Competitive Contexts." Journal of Social Psychology 135:723-36. 